\title{
Changing pattern of respiratory tuberculosis in the UK in adult patients from the Indian subcontinent
}

\author{
L P Ormerod, O R McCarthy, E A Paul
}

\begin{abstract}
Background - Clinical observations over a 12 year period have suggested a changing pattern of adult respiratory tuberculosis in patients from the Indian subcontinent in two districts of the United Kingdom with a high incidence of tuberculosis. Methods - Details of all patients for the period 1981-92 residing in the Newham and Blackburn districts aged 15 and over whose ethnic origin was from the Indian subcontinent $(n=1308)$ were analysed by stepwise logistic regression to determine the relationship between sputum smear positivity, sputum culture positivity, and isolated mediastinal lymphadenopathy, year of notification, age, sex, ethnic group (Indian or Pakistani), and whether the patient had visited the Indian subcontinent within the last three years.

Results - The proportion of cases who were smear positive rose over the 12 years of the study, as did the proportion of culture positive cases. The proportion with isolated mediastinal lymphadenopathy fell. These changes took place in both districts. They were not explained by demographic changes in age, sex, or ethnic group, nor was there evidence that smear and culture positivity increased in those who had recently visited India or Pakistan.

Conclusions - The pattern of tuberculosis in adult patients originating from the Indian subcontinent has altered over time towards that seen in the white population in the UK.

(Thorax 1997;52:802-804)
\end{abstract}

Keywords: tuberculosis, Indian subcontinent.

Infirmary, Blackburn

BB2 3UR, Lancashire,

UK

L P Ormerod

Newham Chest Clinic, Edith Road, London

E6 1DE, UK

O R McCarthy

Department of

Epidemiology and

Medical Statistics,

London Hospital

Medical College,

London E2 9JX, UK

E A Paul

Correspondence to:

Dr L P Ormerod.

Received 5 March 1997

Returned to authors

12 May 1997

Revised version received

27 May 1997

Accepted for publication

30 May 1997

Surveys of tuberculosis notifications in England and Wales in $1978 / 9,{ }^{1} 1983,{ }^{2}$ and $1988^{3}$ by the Medical Research Council showed that persons originating from the Indian subcontinent provided $35-40 \%$ of all notified cases. These cross sectional surveys have shown that the pattern of respiratory disease is different in patients from the Indian subcontinent (ISC) who have a higher proportion of isolated mediastinal lymphadenopathy than other patients and a lower proportion both of sputum smear and of sputum culture positive disease.

In both the $1978 / 9^{4}$ and $1983^{5}$ surveys Blackburn and Newham boroughs were among the 10 local government areas with the highest incidence of tuberculosis out of a total of 403 such areas. Clinical observations in both the Blackburn and Newham Chest Clinics during the 1980s suggested that the pattern of adult respiratory disease in adult patients from the Indian subcontinent might be changing, with the proportion of patients with isolated mediastinal lymphadenopathy decreasing and, conversely, an increasing proportion of sputum smear and sputum culture positive disease appearing. We have used detailed clinical and epidemiological information from data bases providing complete case ascertainment of tuberculosis patients for both districts to test these clinical observations.

\section{Methods}

Details of all notified cases of tuberculosis in patients who were of ISC ethnic origin aged 15 years or over were examined for the years 1981-92 inclusive, Age, sex, ethnic subgroup (Pakistani or Indian), site of disease, and year of diagnosis were known for all patients. Sputum status was divided into four groups: smear and culture positive; smear negative culture positive; smear and culture negative; no sample obtained. Site of disease was recorded as one of five categories - three types of respiratory tuberculosis (pulmonary, pleural effusion, or isolated mediastinal gland disease) and two categories of non-respiratory tuberculosis (peripheral gland or other non-respiratory disease). The year of first entry to the UK (where appropriate) and year of last return visit to the Indian subcontinent was recorded in over $90 \%$ of cases. This information was combined to categorise patients into two groups - those who had been to the Indian subcontinent within the last three years and those who had not. Country of birth was also recorded; however, only 50 patients were born in the UK so these were

\section{STATISTICAL METHODS}

Stepwise logistic regression was used to investigate the relationships between type of disease and six explanatory variables. The explanatory variable of most interest was year of notification to see whether there had been changes over time in the type of disease presenting. Age, sex, and ethnic group were included in the analysis to see whether changes in disease type were related to changes in the had not visited the Indian subcontinent in the last three years was included to see whether population structure. Whether patients had or 
changes were related to increased risk of exposure to tuberculosis. The district was included to see whether the patterns of disease were the same in the two districts.

A series of logistic regression analyses were performed using the following dichotomous variables as the dependent variable. In the whole sample $(n=1308)$ three comparisons were made: sputum smear positive versus sputum smear negative; sputum culture positive versus sputum culture negative, and pulmonary tuberculosis versus all other tuberculosis. Within the group of patients with respiratory disease $(n=786)$ mediastinal gland tuberculosis was compared with other respiratory tuberculosis including pulmonary tuberculosis and pleural effusion. Within those patients with non-respiratory tuberculosis $(n=522)$ peripheral gland tuberculosis was compared with all other non-respiratory tuberculosis. Programs used for analysis were Stata (release 3.1) and SPSS for Windows (release 6.0).

\section{Results}

CLINICAL AND DEMOGRAPHIC DATA

There were 1308 patients of ISC ethnic origin aged 15 years or over (723 female) treated for tuberculosis, 410 of Pakistani and 898 of Indian ethnic origin. Of these, 516 were treated in Blackburn and 792 in Newham. The majority, $786(60 \%)$, had respiratory tuberculosis and, of these, 462 had parenchymal pulmonary disease, 114 pleural effusions, and 210 isolated mediastinal lymphadenopathy. Sputum samples were taken from 493 of the respiratory cases: 172 were smear and culture positive; 117 were smear negative but culture positive; and 204 were negative on both smear and culture. There were 293 respiratory cases for whom no sputum sample was obtained. There were 522 cases of non-respiratory disease, with 277 having peripheral lymphadenopathy and 245 having other non-respiratory disease. Whether the patient had visited the Indian subcontinent in the last three years was known in 1223 cases (94\%), 513 having visited while 710 had not.

\section{STATISTICAL ANALYSIS}

The results of the logistic regression are presented in table 1 . For the total sample the proportion of culture positive patients increased over time with an odds ratio (OR) of 1.10 (95\% confidence interval (CI) 1.06 to 1.14) per year. The proportion with culture

Table 1 Regression analysis of type of tuberculosis with year of notification, district, age, sex, ethnic group and whether visited Indian subcontinent in the last three years in 1308 patients

\begin{tabular}{llllc}
\hline $\begin{array}{l}\text { Outcome variable } \\
\text { (type of tuberculosis) }\end{array}$ & $\begin{array}{l}\text { Explanatory } \\
\text { variable }\end{array}$ & $\begin{array}{l}\text { Odds } \\
\text { ratio }\end{array}$ & $\begin{array}{l}\text { 95\% confidence } \\
\text { interval }\end{array}$ & p value \\
\hline Smear positive & Year notified & 1.06 & 1.01 to 1.11 & 0.017 \\
Culture positive & Year notified & 1.10 & 1.06 to 1.14 & $<0.0005$ \\
& District & 1.58 & 1.21 to 2.08 & $<0.001$ \\
Mediastinal glands & Year notified & 0.95 & 0.90 to 0.97 & 0.036 \\
& Ethnic & 1.80 & 1.12 to 2.61 & 0.004 \\
& District & 0.59 & 0.41 to 0.83 & 0.003 \\
& Age & 0.97 & 0.96 to 0.98 & 0.0005 \\
Peripheral glands & Within UK in & 0.56 & 0.38 to 0.79 & 0.001 \\
& last 3 years & & & \\
\hline
\end{tabular}

positivity was greater in Newham than in Blackburn OR 1.58 (1.21 to 2.08). The increase in smear positive disease per year was slightly smaller (OR 1.06 (1.01 to 1.11)) and there was no significant differences between districts.

The proportion of respiratory cases in the sample decreased over time, though not significantly so. The proportion with tuberculosis of the mediastinal glands decreased over time (OR 0.95 (0.90 to 0.97)). Mediastinal gland tuberculosis was more common in Blackburn than in Newham, in Indians than in Pakistanis, and in younger patients. Only peripheral gland tuberculosis seemed to be related to visits to the Indian subcontinent during the past three years.

The percentage of smear positive respiratory cases increased from $17.4 \%$ in $1981-4$ to $26.6 \%$ in $1989-92$. Culture positivity increased from less than one third $(28.7 \%)$ to over $40 \%$ $(43.7 \%)$. There was a striking change in the percentage of cases with isolated mediastinal gland tuberculosis which almost halved from $20.5 \%$ in $1981-4$ to $11.1 \%$ in $1989-92$.

\section{Discussion}

Logistic regression analysis confirmed that the proportion of both smear and culture positivity had increased over the 12 years from 1981-92, while the proportion of isolated mediastinal lymphadenopathy decreased. These trends occurred in both districts, with the culture positive proportion being greater in Newham than in Blackburn and the proportion with mediastinal lymphadenopathy being greater in Blackburn than in Newham. The changes are felt unlikely to be the result of changing diagnostic criteria over time. The same consultant staff were managing the patients over the whole study period and are not aware of any overt change in their diagnostic criteria and methods. Mediastinal lymphadenopathy occurred more frequently in Indian than in Pakistani patients, a difference in pattern which has been reported before, ${ }^{6}$ and there was also a significant reduction in the proportion of patients with mediastinal lymphadenopathy over time.

Because recent immigration and return visits to the Indian subcontinent have been shown to be a risk factor for tuberculosis, ${ }^{7}$ it seemed possible that the changing pattern of disease seen in Blackburn and Newham might be connected with visits. However, neither the changes in smear or culture positivity nor the reduction in mediastinal gland tuberculosis showed association with visits to the Indian subcontinent. Peripheral gland tuberculosis was higher in those who had made visits, but did not appear to be changing over time. The changing age structure of the population in the UK from the Indian subcontinent could be a factor, but was only shown to be significant in the case of mediastinal lymphadenopathy.

The significant trends seen in two widely separated high incidence districts in this longitudinal study over 12 years are also seen in data from the short cross-sectional Medical Research Council notification surveys of 1978/ $9,{ }^{1} 1983,{ }^{2}$ and $1988,{ }^{3}$ supplemented by un- 
published data (courtesy of Dr J H Darbyshire) which largely overlap with the time period of this report. The proportions of sputum smear positive disease, sputum culture positive disease, and those with isolated mediastinal lymphadenopathy were, respectively, $22 \%$, $41 \%$ and $19 \%$ in $1978 / 9 ; 27 \%, 43 \%$ and $13 \%$ in 1983; and $29 \%, 44 \%$ and $8 \%$ in 1988 .

Patients who are smear positive are much more infectious, ${ }^{8}$ so an increase in the proportion of smear positive cases over time may be contributing to the recent increase in the incidence of tuberculosis which has largely been in the ethnic minority groups ${ }^{9}$ of which the ISC ethnic group is much the most numerous.

The authors would like to thank Boehringer Ingelheim for their financial support of this study.

1 Medical Research Council Tuberculosis and Chest Diseases Unit. National survey of tuberculosis notifications in EngUnit. National survey of tuberculosis notificatio
land and Wales 1978/9. BMF 1980;281:895-8.
2 Medical Research Council Tuberculosis and Chest Diseases Unit. National survey of tuberculosis notifications in England and Wales 1983. BMF 1985;291:658-61.

3 Medical Research Council Cardiothoracic Epidemiology Group. National survey of tuberculosis notifications in England and Wales 1988. Thorax 1992;47:770-5.

4 Medical Research Council Tuberculosis and Chest Diseases Unit. The geographical distribution of tuberculosis noUnit. The geographical distribution of tuberculosis no9). Tubercle 1982;63:75-88

5 Medical Research Council Tuberculosis and Chest Diseases Unit. The geographical distribution of tuberculosis notifications in a national survey of England and Wales in 1983. Tubercle 1976;67:163-78.

6 Ormerod LP, Nunn AJ, Byfield SP, Darbyshire JH. Pattern of tuberculosis in Indian and Pakistani/Bangladeshi patients: effects of age, date of first entry and ethnic group. Respir Med 1991;85:275-80.

7 McCarthy OR. Asian immigrant tuberculosis: the effect of visiting. $\mathrm{Br} \mathcal{F}$ Dis Chest 1984;78:248-53.

8 British Tuberculosis Association. A study of a standardised contact procedure in tuberculosis. Tubercle 1978;59:24559.

9 Watson JM. on behalf of a Public Health Laboratory Service/ British Thoracic Society/Department of Health Collaborative Group Results of a national survey of tuberculosis notifications in England and Wales in 1993. Th 1995;50:442P. 